\title{
Leptospiral Culture without 5'-Fluorouracil Revealed Improved Leptospira Isolation from Febrile Patients in North-Eastern Malaysia
}

\author{
Amira Wahida Mohamad Safiee ${ }^{1}$, Mohammad Ridhuan Mohd Ali ${ }^{2}$, Mohd Hashairi Fauzi ${ }^{3}$, \\ Alwi Muhd Besari ${ }^{4}$, Chan Yean Yean ${ }^{1}$, Vasantha Kumari Neela ${ }^{5}$ and Nabilah Ismail ${ }^{1 \text {,* }}$ \\ 1 Department of Medical Microbiology \& Parasitology, School of Medical Sciences, Universiti Sains Malaysia, \\ Health Campus, Kubang Kerian 16150, Kelantan, Malaysia; amirawahida1712@gmail.com (A.W.M.S.); \\ yychan@usm.my (C.Y.Y.) \\ 2 Bacteriology Unit, Infectious Disease Research Center (IDRC), Institute for Medical Research, \\ Complex National Institutes of Health, Section U13 Setia Alam, Shah Alam 43200, Selangor, Malaysia; \\ ridhuan.ali@gmail.com \\ 3 Department of Emergency Medicine, School of Medical Sciences, Universiti Sains Malaysia, Health Campus, \\ Kubang Kerian 16150, Kelantan, Malaysia; hashairi@usm.my \\ 4 Department of Medicine, School of Medical Sciences, Universiti Sains Malaysia, Health Campus, \\ Kubang Kerian 16150, Kelantan, Malaysia; dralwi@usm.my \\ 5 Department of Medical Microbiology \& Parasitology, Faculty of Medicine and Health Sciences, \\ Universiti Putra Malaysia, Serdang 43400, Malaysia; vasantha@upm.edu.my \\ * Correspondence: drnabilah@usm.my
}

Received: 20 January 2020; Accepted: 15 February 2020; Published: 18 February 2020

\begin{abstract}
Objectives: Isolation of Leptospira by culture represents a definitive growth and confirmation of the disease, yet it is hampered with its nature of slow growth. With slight modification of culture method, the study aims to isolate and characterize Leptospira spp. from patients with acute febrile illness. Methods: A total of 109 blood samples were collected from patients with acute febrile illness that presented at the Emergency Department of Hospital Universiti Sains Malaysia, Malaysia. Clinical samples were subjected to Leptospira IgM Rapid test, microscopic agglutination test (MAT), isolation by culture method, and direct real-time PCR test. For leptospiral isolation, the samples (whole blood and deposit from spun plasma) were cultured into modified Ellinghausen McCullough Johnson Harris (EMJH) media with and without 5 '-fluorouracil (5-FU). In every culture positive sample, partial $16 \mathrm{~S}$ rRNA gene sequencing was performed for molecular identification of the isolates. Phylogenetic analysis was carried out to determine the genetic relatedness among the isolates. An inhibition of 5-FU study was performed on Leptospira interrogans serovar Canicola with different concentrations to compare the growth detection of the tested Leptospira with or without 5-FU within 7 days of incubation. Results: Leptospirosis was diagnosed in $14.7 \%$ of patients with acute febrile illness. Two Leptospira spp. ( $n=2 / 109,1.85 \%)$ were successfully isolated from whole blood and deposit from spun plasma samples. B004 and B208 samples were positive at day 11 and day 7, respectively, in EMJH media without addition of 5-FU. Sample B004 was identified as Leptospira interrogans and B208 as Leptospira weilli. Phylogenetic analysis confirmed that both of them were within pathogenic group and they were not related. The 5-FU inhibition study revealed that additional of 5-FU at final concentration of $200 \mu \mathrm{g} / \mathrm{mL}$ to EMJH media demonstrated an inhibitory effect on the growth of the tested strain Conclusion: Isolation of Leptospira spp. using EMJH media without addition of 5'-fluorouracil resulted in a better outcome. Two pathogenic Leptospira isolates were successfully cultivated from patients with acute febrile illness that were genetically not related.
\end{abstract}

Keywords: isolation; Leptospira; febrile illness; Malaysia 


\section{Introduction}

Leptospirosis is a global re-emerging zoonotic disease and occurs in Malaysia as an endemic disease [1]. It is caused by pathogenic Leptospira that can be isolated from both patients and the environment [2,3]. Leptospirosis cases rise during the floods and seasonal rainfall due to better survival of leptospires and wider transmission in the environment [4].

Leptospira gain entry into the human blood stream through skin abrasions, mucous membrane or cuts, directly from the carrier animals, or indirectly via a contaminated environment. Humans pose higher risk of infection while performing outdoor recreations, domestic activities, or occupations that require interaction with animals, freshwater, and soil [5]. The disease manifests from mild, influenza-like illness to severe complications which may involve renal and hepatic impairment, pulmonary distress, and death. During the acute phase of infection, patients may experience headache, fever, malaise, myalgia, conjunctival suffusion, and transient rash.

Acute febrile illness is one of the common symptoms for patients to seek treatment at the emergency department or hospital care [6,7]. In tropical or developing countries, symptoms of acute febrile illness are undifferentiated in many diseases such as hepatitis, meningitis, dengue, malaria, leptospirosis, typhoid, influenza, viral hemorrhagic fever, icteric fever, and rickettsiosis [6-9]. The undifferentiated acute febrile illness due to leptospirosis ranged from $1.1 \%$ to $29.5 \%$ [6-12].

Isolation of Leptospira by culture represents a definitive confirmation of the disease, yet it is hampered with its nature of slow growth that results in longer culture time [5]. In addition, positive culture rate for Leptospira is generally low $[2,12,13]$. However, once the isolate is obtained, it is very useful for molecular genotyping and epidemiology study. With slight modification of culture method and type of samples used, this study aimed to isolate Leptospira spp. from patients with acute febrile illness in a tertiary teaching hospital in north-eastern Malaysia.

\section{Materials and Methods}

\subsection{Clinical Samples}

Blood samples were obtained from patients presented at the Department of Emergency Medicine, Hospital Universiti Sains Malaysia (HUSM) from January 2017 until December 2017 with acute febrile illness, that fulfilled the inclusion and exclusion criteria. Acute febrile illness was defined as having fever at $38^{\circ} \mathrm{C}$ or higher, and not more than 14 days of illness [6]. Adult patients aged 18 years old and above that presented with fever for up to 14 days with temperature of $38^{\circ} \mathrm{C}$ or more were included in the study. Those with confirmed cases or obvious sources of infection such as abscesses or other infectious diseases such as typhoid fever, dengue, or others, those with immunocompromised conditions such as cancer, HIV disease, or renal failure, or those already on antibiotics were excluded from the study. Written informed consent was obtained prior to sample collection. The blood samples for each patient comprised of $2 \mathrm{~mL}$ of blood in a plain tube for rapid Leptospira serology test, $2 \mathrm{~mL}$ of blood in an EDTA tube for molecular detection, and $4 \mathrm{~mL}$ of blood in a heparinized tube for isolation of Leptospira.

\subsection{Rapid Leptospira Serology Test}

This Leptospira IgM Duo Rapid (ImmuneMed, Gangwon-do, Korea) is a semi-quantitative immunochromatography test for the detection of antibodies against Leptospira in the patients' serum following manufacturer's instruction. About $3 \mu \mathrm{L}$ of serum sample was directly placed on the cassette hole followed by adding seven drops of sample diluents. Results were read and interpreted after $15 \mathrm{~min}$.

The test was valid if the red line appeared on the control line. Positivity was denoted by the presence of the red color line in T in both windows which are P 50 and N 200 (Figure 1). Then, the intermediate result was interpreted by the presence of the red color line in $\mathrm{T}$ in the P 50 window. Intermediate results were interpreted according to the region itself as Malaysia is an endemic region 
for leptospirosis. It was recommended by the manufacturer that the test result should be interpreted as intermediate or inconclusive rather than positive, and it was necessary to repeat the test within 2-7 days, if in an epidemic region, that results were interpreted as positive. IgM cut-off titer 50 and 200 were provided and could be used for probable diagnosis at any area in the world including epidemic and endemic regions. Figure 1 shows examples for the positive, intermediate, and negative results for the test. Samples with intermediate and positive results were further subjected to microscopic agglutination test (MAT) as the gold standard test for leptospirosis.

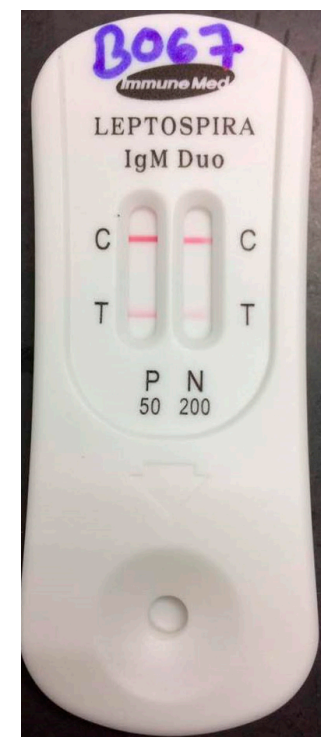

(A)Positive

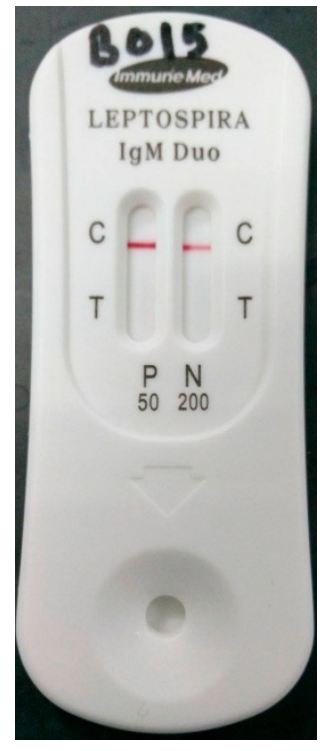

(B)Negative

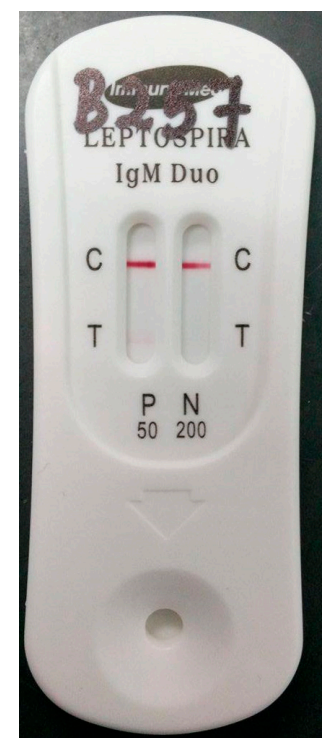

(C)Intermediate

Figure 1. Example of the results for Leptospira IgM Duo Rapid test.

\subsection{Microscopic Agglutination Test}

The microscopic agglutination test (MAT) was performed following the standard method [14]. Serum samples were serially diluted in microtiter plates and live Leptospira serovars were added to each well. A panel of 20 reference Leptospira serovars included Australis, Autumnalis, Bataviae, Canicola, Icterohaemorrhagiae, Celledoni, Grippotyphosa, Javanica, Pomona, Tarassovi, Semaranga, Djasiman, Lai, Copenhageni, Melaka (IMR LEP 1), Sarawak (IMR LEP 175), Hardjobovis (IMR LEP 22), IMR LEP 127, IMR LEP 113, and IMR LEP 131 as recommended by the Institute for Medical Research (IMR), Malaysia. The plates were then incubated for $2 \mathrm{~h}$ at $30{ }^{\circ} \mathrm{C}$ and examined using a dark field microscope. Agglutination of at least $50 \%$ of the leptospires compared to the control culture was considered as positive. A single MAT titer of 1:400 or more was used as cut off point for seropositive results. This titer was specifically recommended by the IMR as the national reference laboratory, and it was based on the background exposure and seroprevalence of leptospirosis in the country.

\subsection{Direct Molecular Detection by Real-Time PCR}

\subsubsection{Extraction of Genomic DNA}

The clinical samples were extracted using the Qiagen QIAamp DNA Blood Mini Kit according to the manufacturer's instructions.

\subsubsection{Detection of Leptospira by Real-Time PCR}

The amplification of the DNA was conducted in PCR buffer containing $1 \times$ SsoAdvanced $^{\mathrm{TM}}$ Universal Probes Supermix (Bio-Rad, Hercules, CA, USA), 200 nM forward primer, 200 nM reverse 
primer, $100 \mathrm{nM}$ probe for both target and internal control genes, $8 \mu \mathrm{L}$ DNA template with the total volume of $20 \mu \mathrm{L}$. The primer and probe sequences were obtained from a previous study [15]. The mixture was subjected into thermal cycler Biorad CFX96 for amplification process; initial denaturation step at $95^{\circ} \mathrm{C}$ for $5 \mathrm{~min}, 50$ cycles of $95^{\circ} \mathrm{C}$ for $30 \mathrm{~s}$, and $61.3^{\circ} \mathrm{C}$ for $30 \mathrm{~s}$. Positivity was indicated by any quantification cycle, $\mathrm{Cq}$ value $\leq 40$ with the baseline threshold was set at 25 [15].

\subsection{Isolation of Leptospira}

Blood samples in a heparinized tube were collected for isolation of Leptospira [12]. Two types of blood samples which were whole blood and deposit from spun plasma were used. For preparation of the deposit from spun plasma, $3 \mathrm{~mL}$ of whole blood was transferred into a new tube as described by a previous method [2]. The sample was then centrifuged at $6000 \mathrm{rpm}$ for $3 \mathrm{~min}$ to get the deposit. The supernatant was removed and $200 \mu \mathrm{L}$ of deposit was left for inoculation into the culture media. Whole blood and deposit from spun plasma were cultured in $5 \mathrm{~mL}$ modified Ellinghausen McCullough Johnson Harris (EMJH) medium following the standard method [14]. The medium was incorporated with different concentrations of 5 '-fluorouracil (5-FU) $(0.2$ and $0.4 \mathrm{mg} / \mathrm{mL}$ of antibiotic concentration) and without antibiotic. 5-FU was added into media because Leptospira is resistant to 5-fluorouracil and it suppressed the growth of contaminating bacteria [14].

Briefly, $100 \mu \mathrm{L}$ of whole blood and $200 \mu \mathrm{L}$ deposit of spun plasma were inoculated into liquid EMJH medium. Cultures were then incubated at $30^{\circ} \mathrm{C}$ in incubator shaker $(40 \mathrm{rpm})$ for 6 months and were examined weekly or fortnightly under the dark-field microscope. Reference strains from Research Laboratory, Department of Medical Microbiology and Parasitology, Universiti Sains Malaysia were included as positive controls. If the leptospires were not detectable after 6 months of incubation, the sample was considered to be negative. Meanwhile, presence of at least four Leptospira under darkfield microscope was considered as a positive result [16].

\subsection{Molecular Characterization of the Isolates}

\subsubsection{DNA Extraction}

Genomic DNA were extracted from positive EMJH culture using Qiagen DNeasy ${ }^{\circledR}$ Blood and Tissue Kit (Qiagen, Hilden, Germany) according to the manufacturer's protocol without modifications. The quantity of DNA was measured by Biophotometer (Eppendorf, Germany). The genomic DNA was stored at $-20^{\circ} \mathrm{C}$ for further uses.

\subsubsection{PCR and Visualization of Products}

PCR were performed by preparing $25 \mu \mathrm{L}$ reaction containing $1 \mathrm{mM}$ forward primer (BakII-F: 5'-AGTTTGATCMTGGCTCAG-3'), 1 mM reverse primer (BakII-R: 5'-GGACTACHAGGG TATCTAAT-3'), $12.5 \mu \mathrm{L}$ of DreamTaq Green PCR Master Mix (Thermo Scientific, Malaysia), $2 \mu \mathrm{L}$ of DNA template, and $8 \mu \mathrm{L}$ DNase-free water. Reaction mixtures were then subjected to cycling conditions that consisted of an initial denaturation step at $95{ }^{\circ} \mathrm{C}$ for $5 \mathrm{~min}$, followed by 30 amplification cycles of denaturation at $95^{\circ} \mathrm{C}$ for $3 \mathrm{~s}$, annealing at $52^{\circ} \mathrm{C}$ for $30 \mathrm{~s}$, and extension at $72{ }^{\circ} \mathrm{C}$ for $30 \mathrm{~s}$. A final extension step was performed at $72{ }^{\circ} \mathrm{C}$ for $5 \mathrm{~min}$. The PCR products were subjected to electrophoresis on a $1.5 \%$ agarose gel in $0.5 \times \mathrm{TBE}$ buffer at $150 \mathrm{~V}$ for $5 \mathrm{~min}$ followed by $80 \mathrm{~V}$ for $60 \mathrm{~min}$. The gel was imaging under UV light using gel image analyzer (Syngene, Cambridge, UK).

\subsubsection{Sequencing and Sequence Analysis}

The PCR products were sequenced by First BASE, Selangor, Malaysia. Biological sequence alignment editor (VectorNTI) and the contig result were compared with the GenBank database using BLAST. 


\subsubsection{Phylogenetic Analysis of $16 \mathrm{~S}$ rRNA Gene Sequences}

The partial sequences of $16 \mathrm{~S}$ rRNA gene ( $r r s$ ) were used to analyze the genetic relatedness of the isolates. A phylogenetic tree was created based on aligned sequences using neighbor joining method in MEGA 7 software [17]. The strains used to construct phylogenetic tree were selected based on $16 \mathrm{~S}$ rRNA gene. The details of strains used were stated at Table 1 .

Table 1. Strains studied and their $16 \mathrm{~S}$ rRNA gene Genbank accession numbers.

\begin{tabular}{cc}
\hline Reference Strain & Accession Number \\
\hline Leptospira weilii Celledoni & AY631877 \\
Leptospira borgpeterseni Veldrat Batavia 46 & AY887899 \\
Leptospira alexanderi L60 & AY631880 \\
Leptospira santarosai LT 821 & AY631883 \\
Leptospira noguchii CZ 214 & AY631886 \\
Leptospira kirschneri 3522 C & AY631895 \\
Leptospira interrogans RGA & AY631894 \\
Leptospira vanthielii Waz Holland & AY631897 \\
Leptospira biflexa Patoc 1 & AY631876 \\
Leptospira wolbachii CDC & AY631879 \\
Leptospira terpstrae LT 11-33 & AY631888 \\
Leptospira meyeri Iowa City Frog & AY631878 \\
Leptospira yanagawae Sao Paulo & AY631882 \\
Leptonema illini 3055 & AY714984 \\
Leptospira fainei BUT 6 & AY631885 \\
Leptospira broomii 5399 & AY796065 \\
Leptospira inadai 10 & AY631896 \\
\hline Leptospira alstonii SSW20 & KY411398 \\
Leptospira idonii LS 0001/15 & KX452326 \\
\hline Leptospira kmetyi Bejo-Iso9 & AB279549 \\
\hline Leptospira licerasiae MMD835 & KT338879 \\
\hline Leptospira wolffii Khorat-H2 & EF612287 \\
\hline & EF025496 \\
\hline
\end{tabular}

\subsection{Inhibition of 5'-Fluorouracil Study}

A reference strain of Leptospira interrogans serovar Canicola was used in this inhibitory study. The initial concentration of Leptospira was $10^{8}$ cells $/ \mathrm{mL}$ followed by a serial dilution until 10 cells $/ \mathrm{mL}$. Leptospira concentration was checked by spectrophotometer at optical density of 0.320 at $420 \mathrm{~nm}$. Approximately at 0.320 , Leptospira concentration was $\approx 10^{8}$ per $\mathrm{mL}[18]$ and was confirmed under dark-field microscopy observation detected to be approximately $10^{7}$ to $10^{8}$ cell/ $/ \mathrm{mL}$ with $100 \%$ active motility.

The EMJH media was added with 5-FU at concentration $0.2 \mathrm{mg} / \mathrm{mL}$. The media containing 5-FU was compared with the media without 5-FU to observe the effect of Leptospira growth. 5-FU was used as antibiotic inside the media because leptospires is resistant to 5-FU and to suppress the growth of contaminating bacteria [14]. Besides that, EMJH containing 5-FU is broadly used for the selective isolation of Leptospira, although it does not inhibit most of the Gram negative bacteria and fungi [19]. The cultures were incubated in incubator shaker at $40 \mathrm{rpm}, 30^{\circ} \mathrm{C}$ for 7 days and were checked every day until day 7 under dark-field microscope for the viability of leptospires. Leptospires concentration was also checked using a tunable microplate reader at optical density of $400 \mathrm{~nm}$. The test was done in duplicate. 


\section{Results}

A total of 109 blood samples were collected from patients with acute febrile illness with not more than 14 days of fever. Two Leptospira spp. $(n=2 / 109,1.85 \%)$ were successfully isolated from whole blood and deposit from spun plasma samples. B004 and B208 samples were positive at day 11 and day 7, respectively, in EMJH media without addition of 5-FU. However, the media containing 5-FU did not show any growth of Leptospira.

Following positive growth, Leptospira isolates (B004 and B208) were identified by partial sequencing of $16 \mathrm{~S}$ rRNA gene $(r r s)$. The partial sequences of the 16S rRNA gene (rrs) showed that B004 and B208 isolates belonged to the pathogenic group of Leptospira which were Leptospira interrogans and Leptospira weilli, respectively. The evolutionary history was inferred using the neighbor-joining method [20]. The optimal tree with the sum of branch length $=0.42237988$ is shown in Figure 2 . The tree was drawn to scale, with branch lengths in the same units as those of the evolutionary distances used to infer the phylogenetic tree. The evolutionary distances were computed using the maximum composite likelihood method [21] and were in the units of the number of base substitutions per site. All positions containing gaps and missing data were eliminated. There were a total of 480 positions in the final dataset.

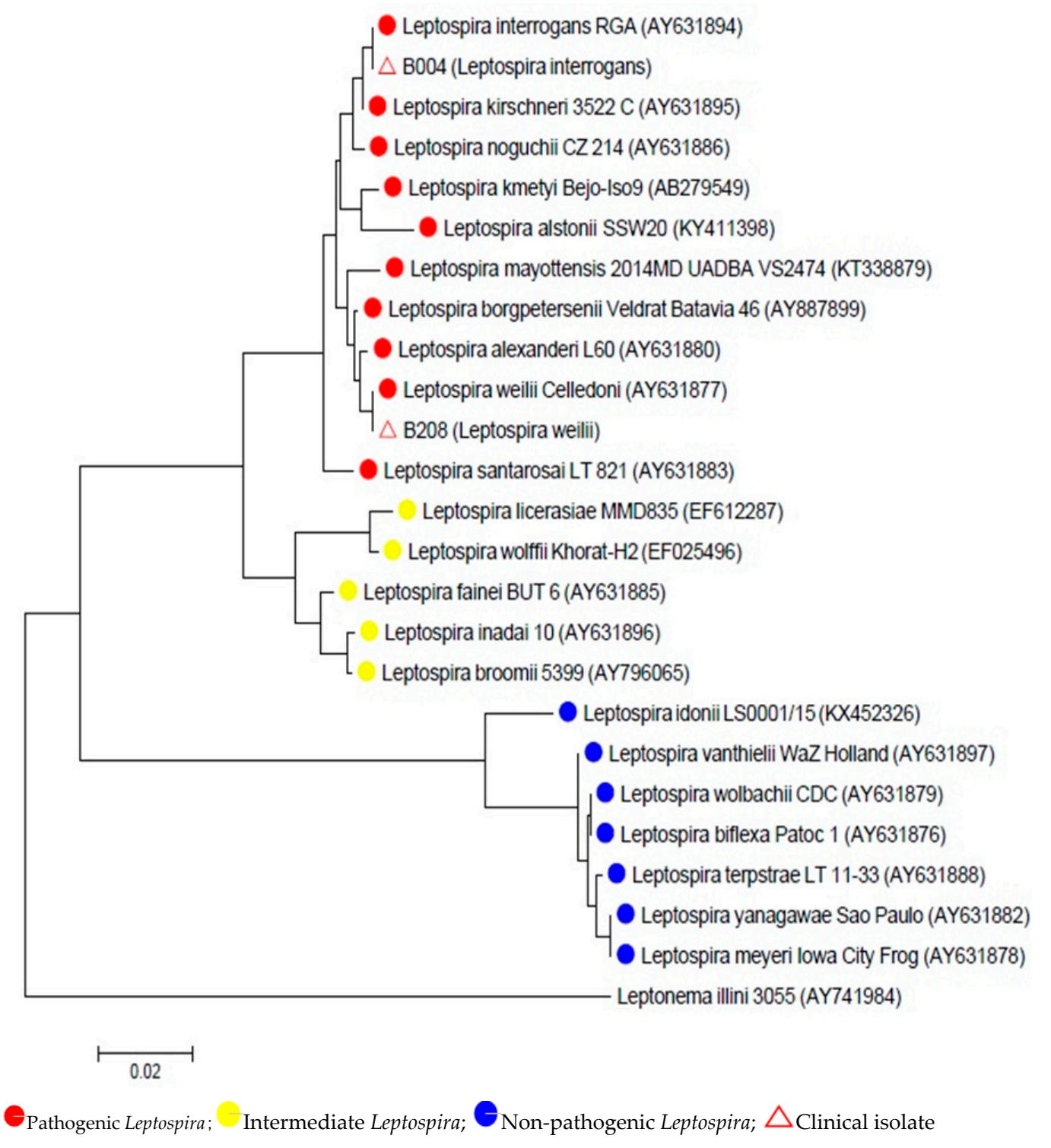

Figure 2. This phylogenetic tree showing evolutionary relationships of taxa of Leptospira spp. and the analysis confirmed that B004 and B208 were within pathogenic group. 
Based on the serological results in Table 2, MAT results were negative for all samples tested (those with intermediate and positive results of Leptospira IgM Duo Rapid). Since all titrations were below 1:400, the positive results were not significant. Real-time PCR from direct clinical samples (Table 2$)$ showed that $14.7 \%(n=16 / 109)$ of the samples were positive including B004 and B208 samples. Therefore, leptospirosis was confirmed in $14.7 \%$ of the patients with acute febrile illness in this study.

Table 2. Results of serological and real-time PCR.

\begin{tabular}{ccc}
\hline $\begin{array}{c}\text { Leptospira IgM Duo Rapid } \\
(\boldsymbol{n}=\mathbf{1 0 9 )}\end{array}$ & $\begin{array}{c}\text { Microscopic Agglutination } \\
\text { Test, Titer }(\boldsymbol{n}=\mathbf{3 1})\end{array}$ & $\begin{array}{c}\text { Real-Time PCR } \\
(\boldsymbol{n}=\mathbf{1 0 9 )}\end{array}$ \\
\hline Intermediate (28) & $1: 100(3)$ & Positive (16) \\
Positive (3) & $1: 50(6)$ & Negative (93) \\
Negative (78) & Negative (22) & \\
\hline
\end{tabular}

In the 5-FU inhibitory study (Table 3), the growth of Leptospira interrogans serovar Canicola was detected as early as day 6 in EMJH media without 5-FU at concentration of $10^{1}-10^{3}$ cells $/ \mathrm{mL}$ and the growth of those cultured in EMJH media with 5-FU was detected at concentration of $10^{3}$ cells $/ \mathrm{mL}$ at day 7. At concentration of $10^{4}$ cells $/ \mathrm{mL}$, the isolate was detected as early as day 4 in EMJH media without 5-FU compared to those with 5-FU, the growth was detected at day 7 . Using a microplate reader at optical density of $400 \mathrm{~nm}$ (Figure 3), Leptospira in EMJH media without 5-FU was detected earlier than those in EMJH media with 5-FU.

Table 3. Microscopic observation under dark-field microscope for culture of Leptospira interrogans serovar Canicola with and without 5'-fluorouracil $(200 \mu \mathrm{g} / \mathrm{mL})$.

\begin{tabular}{|c|c|c|c|c|c|c|c|c|c|c|c|c|c|c|c|}
\hline \multirow{2}{*}{\multicolumn{2}{|c|}{$\begin{array}{l}\text { Leptospira } \\
\text { Concentration } \\
\text { (cells/mL) }\end{array}$}} & \multicolumn{2}{|c|}{ Day 1} & \multicolumn{2}{|c|}{ Day 2} & \multicolumn{2}{|c|}{ Day 3} & \multicolumn{2}{|c|}{ Day 4} & \multicolumn{2}{|c|}{ Day 5} & \multicolumn{2}{|c|}{ Day 6} & \multicolumn{2}{|c|}{ Day 7} \\
\hline & & 5-FU & $\begin{array}{l}\text { No } \\
\text { 5-FU }\end{array}$ & 5-FU & $\begin{array}{l}\text { No } \\
\text { 5-FU }\end{array}$ & 5-FU & $\begin{array}{l}\text { No } \\
\text { 5-FU }\end{array}$ & 5-FU & $\begin{array}{l}\text { No } \\
\text { 5-FU }\end{array}$ & 5-FU & $\begin{array}{l}\text { No } \\
\text { 5-FU }\end{array}$ & 5-FU & $\begin{array}{l}\text { No } \\
\text { 5-FU }\end{array}$ & 5-FU & $\begin{array}{l}\text { No } \\
\text { 5-FU }\end{array}$ \\
\hline \multirow{2}{*}{$10^{8}$} & I & + & + & + & + & + & + & + & + & + & + & + & + & + & + \\
\hline & II & + & + & + & + & + & + & + & + & + & + & + & + & + & + \\
\hline \multirow{2}{*}{$10^{7}$} & I & + & + & + & + & + & + & + & + & + & + & + & + & + & + \\
\hline & II & + & + & + & + & + & + & + & + & + & + & + & + & + & + \\
\hline \multirow{2}{*}{$10^{6}$} & I & + & + & + & + & + & + & + & + & + & + & + & + & + & + \\
\hline & II & + & + & + & + & + & + & + & + & + & + & + & + & + & + \\
\hline \multirow{2}{*}{$10^{5}$} & I & - & - & - & - & - & - & + & + & + & + & + & + & + & + \\
\hline & II & - & - & - & - & - & - & + & + & + & + & + & + & + & + \\
\hline \multirow{2}{*}{$10^{4}$} & I & - & - & - & - & - & - & - & + & - & + & - & + & + & + \\
\hline & II & - & - & - & - & - & - & - & + & - & + & - & + & + & + \\
\hline \multirow{2}{*}{$10^{3}$} & I & - & - & - & - & - & - & - & - & - & - & - & + & + & + \\
\hline & II & - & - & - & - & - & - & - & - & - & - & - & + & + & + \\
\hline \multirow{2}{*}{$10^{2}$} & I & - & - & - & - & - & - & - & - & - & - & - & + & - & + \\
\hline & II & - & - & - & - & - & - & - & - & - & - & - & + & - & + \\
\hline \multirow{2}{*}{$10^{1}$} & I & - & - & - & - & - & - & - & - & - & - & - & + & - & + \\
\hline & II & - & - & - & - & - & - & - & - & - & - & - & + & - & + \\
\hline
\end{tabular}




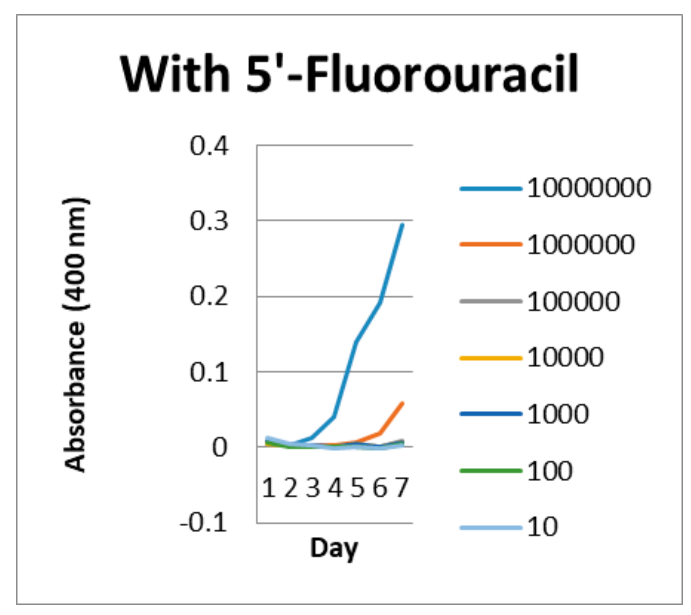

(a)

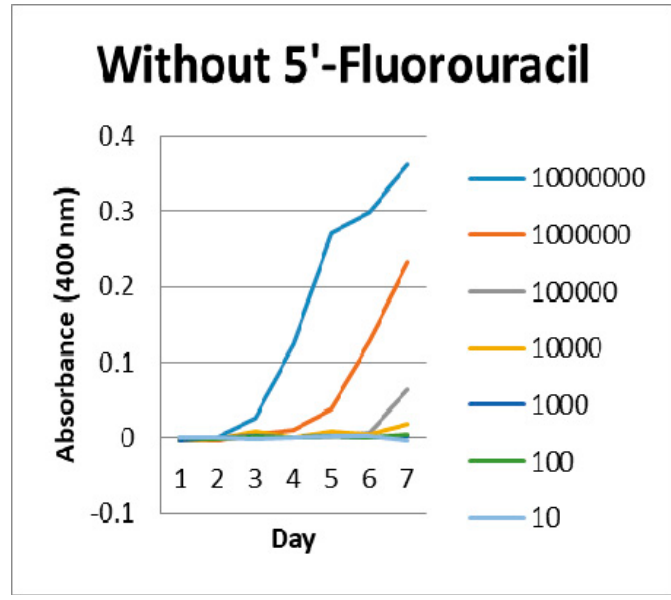

(b)

Figure 3. Graph of Leptospira growth with (a) addition of 5'-fluorouracil and (b) without addition of 5 -fluorouracil measured by microplate reader.

\section{Discussion}

The diagnosis of leptospirosis is confirmed either by MAT or isolation by culture or nucleic acid detection by PCR from clinical samples. Our study showed that $14.7 \%(n=16 / 109)$ of the patients were diagnosed as leptospirosis based on positive real-time PCR and culture results. All samples were negative by MAT as the titers were below 1:400. Since the samples were collected during the acute phase of the illness, the specific antibody production against Leptospira was low and expected to rise during the convalescent stage. Moreover, the sensitivity of the MAT during the acute phase of illness is low and needs a paired serum to confirm the diagnosis [22], however, it was impossible to trace the patients once they returned to their houses.

Generally, the low isolation of Leptospira from blood samples has been the main problem since a long time ago. In this study, $1.85 \%(n=2 / 109)$ of Leptospira spp. was successfully isolated from patients presenting with acute febrile illness. Previous studies also reported a low recovery rate for Leptospira, but higher than our study, ranging from $7.2 \%$ to $9.0 \%[2,12,13]$ of the samples.

Many factors influence the positivity rate of leptospiral culture from blood samples. Blood culture should be taken as soon as possible after the patients' presentation because Leptospira can be isolated in the bloodstream during the leptospiremia phase that occurs during the acute stage of the illness, however the numbers will decrease up to 15 days [23]. Moreover, a previous study reported the maximum duration of fever in patients with positive culture for Leptospira in their blood samples was 5 days [2]. Other study also reported that Leptospira can be isolated from blood or CSF samples during the first week of illness which is 7-10 days [24]. Thus, the patients with a fever for no more than 14 days were recruited in this study to increase the rate of Leptospira isolation. Furthermore, patients with prior antibiotic treatment were excluded from the study since antibiotics quickly remove Leptospira from the blood [25].

In an ideal circumstance, sample inoculation at the patients' bedside is highly recommended in order to increase positive growth of Leptospira [26]. However, the technique was not applicable in this study due to the logistical problems. To minimize the potential of lower isolation rate, the blood samples were transported to the laboratory immediately at ambient temperature. Nevertheless, it is believed that such procedure was not the reason for the low recovery of Leptospira since the longest reported period to recover Leptospira from heparinized blood kept at room temperature was 109 days [2].

The type of blood specimens and its volume affects the recovery rate for Leptospira spp. The standard method is to inoculate one to five drops $(100-200 \mu \mathrm{L})$ of whole blood directly into EMJH media. The low volume of whole blood used for culturing aims to avoid the inhibition of leptospiral 
growth by haemoglobin, antibiotics, antibodies, and other blood components factors [27,28]. For the greatest recovery rate, multiple samples should be taken for culture, but this is almost impossible. The type and modification of media used have also been studied. The use of a noble agar base supplemented with $10 \%$ rabbit serum (named LVW agar) enables rapid growth, isolation of single colonies, and simple antimicrobial susceptibility testing for Leptospira spp. [29]. In addition, Leptospira is a fastidious organism and slow grower, making the culture technique very tedious, difficult, and can take up to three months.

Patient factors for low recovery of Leptospira might be due to delayed patient presentation and the exact duration of the illness was not disclosed exactly in medical history of patient. To get good samples for isolation study, patients should come for blood investigation as early as possible. Some of them might already take antibiotics prescribed by a general practitioner, but this information was not disclosed during data collection. Some patients with severe illness were unable to disclose the medical history, hence, sole interviews with the spouses, relatives, or companions were carried out. Moreover, this study was conducted at a tertiary teaching hospital located within the capital city of an urban area. Most of the recruited patients in this study stayed within the capital city, hence, they probably went to the nearest private clinic to seek initial treatment for acute febrile illness before attending our hospital at a later phase of the infection.

Isolation of Leptospira from clinical samples gives a definitive diagnosis of leptospirosis and also aids in identifying the prevalent species. This study used $16 \mathrm{~S}$ rRNA gene sequence analysis for species identification of Leptospira. 16S rRNA gene sequencing is a common technique for the identification of unknown bacterial isolates, especially those of fastidious organisms such as Leptospira species [30]. Both of the isolates namely L. interrogans and L. weilii belonged to the pathogenic group of Leptospira. The phylogenetic tree confirmed the genetic relationships between Leptospira with distinct clades comprised of pathogenic, intermediate, and non-pathogenetic species (Table 3). The clinical isolates were comprised in the pathogenic group, however, the species was different and not related. The phylogenetic tree was constructed based on the 16S rRNA gene using one locus therefore the gene cannot be used for differentiation within the species. L. interrogans was the most predominant pathogenic Leptospira isolated from clinical samples such as blood and urine in human and animals [31-33]. In addition, other important serogroups from this species include Australis, Autumnalis, Canicola, Icterohaemorrhagiae, Pomona, Pyrogenes, and Sejroe [34]. Interestingly, L. weilii is not commonly isolated from the clinical samples. L. weilii strain Celledoni was first isolated from the blood of a patient from North Queensland, Australia [35]. Another previous study reported L. weilii serovar Topaz, a newly described serovar isolated from human and animal samples mainly from Far North Queensland [36].

In this study, both B004 and B028 isolates that were cultured in EMJH media without addition of 5 -FU gave better performance of leptospiral growth than media containing the antibiotic. A previous study found that 5-FU is fatal to various microorganisms but not to Leptospira [37]. This compound was used widely to minimize the contamination and to obtain pure primary cultures isolates [37]. However, certain strains of Leptospira may be inhibited by 5-FU [38]. Report of a WHO expert group suggested to use both media with and without 5-FU simultaneously for the primary isolation of Leptospira spp. [39].

In 5-FU inhibitory study, the growth of Leptospira interrogans serovar Canicola was detected as early as day 6 in EMJH media without 5-FU at concentration of $10^{1}-10^{3}$ cells $/ \mathrm{mL}$ and for those with 5-FU, the growth was detected at concentration of $10^{3}$ cells $/ \mathrm{mL}$ at day 7 . At concentration of $10^{4}$ cells $/ \mathrm{mL}$, the isolate was detected as early as day 4 in EMJH media without 5-FU whereas for those with 5-FU, the growth was detected 3 days later at day 7. In contrast to a previous study, they reported the use of 5-FU at a concentration of 50-1000 $\mu \mathrm{g} / \mathrm{mL}$ did not inhibit the growth of Australis, Canicola, and Pomona serovars when those isolates were incubated at $30^{\circ} \mathrm{C}$ for 7 days [37]. It was also demonstrated that 5-FU was not incorporated into Pomona serovar nucleic acids [37]. Our experimental study suggests that additional of 5-FU at final concentration of $200 \mu \mathrm{g} / \mathrm{mL}$ to EMJH media revealed an inhibitory effect 
on the growth of the tested strain. Therefore, this experimental study supports our earlier finding that leptospiral culture on EMJH media without addition of 5-FU resulted in a better outcome.

\section{Conclusions}

Leptospirosis was diagnosed in $14.7 \%$ of patients with acute febrile illness. Two pathogenic Leptospira isolates were successfully cultivated and both of them were genetically not related. Low isolation of Leptospira was contributed by many factors. Leptospiral culture on EMJH media without addition of 5-FU resulted in a better outcome. More comprehensive research to optimize the culture method is necessary for improved isolation of Leptospira spp. for further epidemiology and molecular characterization studies.

Author Contributions: Conceptualization, N.I. and C.Y.Y.; Data curation, A.W.M.S. and M.R.M.A.; Formal analysis, A.W.M.S. and M.R.M.A.; Funding acquisition, N.I. and C.Y.Y.; Investigation, A.W.M.S., M.R.M.A., M.H.F., A.M.B., and V.K.N.; Project administration, N.I. and A.W.M.S.; Resources, M.H.F., A.M.B., C.Y.Y., V.K.N., and N.I.; Supervision, N.I. and C.Y.Y.; Writing—original draft, A.W.M.S.; Writing—review and editing, N.I. and A.W.M.S. All authors have read and agreed to the published version of the manuscript.

Funding: This study was funded by Long Term Research Grant Scheme (203/PPSP/6770004), Research University Grant (1001/PPSP/812144) and Bridging Grant (304/PPSP/6316183). The second author is supported by Public Service Department (JPA) Malaysia through the Yang di-Pertuan Agong Scholarship program and the Ministry of Health Malaysia.

Acknowledgments: We would like to thank the Hospital Universiti Sains Malaysia for allowing us to use all the data and facilities for the study. Special thanks also to the staff at the Department of Medical Microbiology and Parasitology, Universiti Sains Malaysia for the direct and indirect contributions.

Conflicts of Interest: The authors declare no conflict of interest.

Ethical Approval: This study was approved by the Human Research Ethics Committee USM (USM/JEPeM/16090300).

\section{References}

1. El, I.J.; Bahaman, A.R. A review of human leptospirosis in Malaysia. Trop. Biomed. 2004, 21, 113-119.

2. Wuthiekanun, V.; Chierakul, W.; Limmathurotsakul, D.; Smythe, L.D.; Symonds, M.L.; Dohnt, M.F.; Slack, A.T.; Limpaiboon, R.; Suputtamongkol, Y.; White, N.J.; et al. Optimization of Culture of Leptospira from Humans with Leptospirosis. J. Clin. Microbiol. 2007, 45, 1363-1365. [CrossRef]

3. Azali, M.A.; Yean Yean, C.; Harun, A.; Aminuddin Baki, N.N.; Ismail, N. Molecular Characterization of Leptospira spp. in environmental samples from north-eastern Malaysia revealed a pathogenic strain, Leptospira alstonii. J. Trop. Med. 2016, 2016. [CrossRef] [PubMed]

4. Coelho, M.S.Z.S.; Massad, E. The impact of climate on Leptospirosis in Sao Paulo, Brazil. Int. J. Biometeorol. 2012, 56, 233-241. [CrossRef] [PubMed]

5. Adler, B.; de la Peña-Moctezuma, A. Leptospira and leptospirosis. Vet. Microbiol. 2010, 140, $287-296$. [CrossRef] [PubMed]

6. Kashinkunti, M.D.; Gundikeri, S.K.; Dhananjaya, M. Acute undifferentiated febrile illness-clinical spectrum and outcome from a tertiary care teaching hospital of north Karnataka. Int. J. Biol. Med. Res. 2013, 3, 3399-3402.

7. Tun, Z.M.; Moorthy, M.; Linster, M.; Su, Y.C.; Coker, R.J.; Ooi, E.E.; Low, J.G.; Smith, G.J.; Tam, C.C. Characteristics of acute febrile illness and determinants of illness recovery among adults presenting to Singapore primary care clinics. BMC Infect. Dis. 2016, 16, 612. [CrossRef]

8. Rafizah, A.N.; Aziah, B.D.; Azwany, Y.N.; Imran, M.K.; Rusli, A.M.; Nazri, S.M.; Nabilah, I.; Asma, H.S.; Zahiruddin, W.M.; Zaliha, I. Leptospirosis in Northeastern Malaysia: Misdiagnosed or Coinfection? Int. J. Collab. Res. Intern. Med. Public Health 2012, 47, 1419-1427.

9. Leelarasamee, A.; Chupaprawan, C.; Chenchittikul, M.; Udompanthurat, S. Etiologies of acute undifferentiated febrile illness in Thailand. J. Med. Assoc. Thail. 2004, 87, 464-472.

10. Manocha, H.; Ghoshal, U.; Singh, S.K.; Kishore, J.; Ayyagari, A. Frequency of leptospirosis in patients of acute febrile illness in Uttar Pradesh. J. Assoc. Phys. India 2004, 52, 623-625. 
11. Suttinont, C.; Losuwanaluk, K.; Niwatayakul, K.; Hoontrakul, S.; Intaranongpai, W.; Silpasakorn, S.; Suwancharoen, D.; Panlar, P.; Saisongkorh, W.; Rolain, J.M.; et al. Causes of acute, undifferentiated, febrile illness in rural Thailand: Results of a prospective observational study. Ann. Trop. Med. Parasitol. 2006, 100, 363-370. [CrossRef] [PubMed]

12. Sarwankar, A.; Mulla, S. Isolation of Leptospira in suspected cases of leptospirosis: Is heparinized whole blood a better modality. Int. J. Adv. Sci. Eng. Technol. 2016, 4, 150-152.

13. Boonsilp, S.; Thaipadungpanit, J.; Amornchai, P.; Wuthiekanun, V. Molecular detection and speciation of pathogenic Leptospira spp. in blood from patients with culture-negative leptospirosis. BMC Infect. Dis. 2011, 11, 338. [CrossRef] [PubMed]

14. World Health Organization. Human leptospirosis: Guidance for diagnosis, surveillance and control. WHO Libr. 2003, 45, 1-109. [CrossRef]

15. Ali, M.R.; Safee, A.W.; Ismail, N.H.; Sapian, R.A.; Hussin, H.M.; Ismail, N.; Yean, C.Y. Development and validation of pan-Leptospira Taqman qPCR for the detection of Leptospira spp. in clinical specimens. Mol. Cell. Probes 2018, 38, 1-6.

16. Issazadeh, K.; Amirmozaffari, N.; Mehrabian, S.; Oryan, S. Assessment of Distribution Leptospira spp. in Surface Waters of Guilan Province. World J. Zool. 2009, 4, 79-84.

17. Kumar, S.; Stecher, G.; Tamura, K. MEGA7: Molecular Evolutionary Genetics Analysis Version 7.0 for Bigger Datasets. Mol. Biol. Evol. 2016, 33, 1870-1874. [CrossRef]

18. Moreno, L.Z.; Miraglia, F.; Lilenbaum, W.; Neto, J.S.; Freitas, J.C.; Morais, Z.M.; Hartskeerl, R.A.; Da Costa, B.L.; Vasconcellos, S.A.; Moreno, A.M. Profiling of Leptospira interrogans, L. santarosai, L. meyeri and L. borgpetersenii by SE-AFLP, PFGE and susceptibility testing- a continuous attempt at species and serovar differentiation. Emerg. Microbes Infect. 2016, 5, 1-7. [CrossRef]

19. Chakraborty, A.; Miyahara, S.; Villanueva, S.Y.A.M.; Saito, M.; Gloriani, N.G.; Yoshida, S.-I. A novel combination of selective agents for isolation of Leptospira species. Microbiol. Immunol. 2011, 55, 494-501. [CrossRef]

20. Saitou, N.; Nei, M. The neighbour-joining method: A new method for reconstructing phylogenetic trees. Mol. Biol. Evol. 1987, 4, 406-425.

21. Tamura, K.; Nei, M.; Kumar, S. Prospects for inferring very large phylogenies by using the neighbor-joining method. Proc. Natl. Acad. Sci. USA 2004, 101, 11030-11035. [CrossRef] [PubMed]

22. Chappel, R.J.; Goris, M.; Palmer, M.F.; Hartskeerl, R.A. Impact of proficiency testing on results of the microscopic agglutination test for diagnosis of leptospirosis. J. Clin. Microbiol. 2004, 42, 5484-5488. [CrossRef] [PubMed]

23. Haake, D.A.; Levett, P.N. Leptospirosis in humans. Curr. Top. Microbiol. Immunol. 2015, 387, 65-97. [CrossRef] [PubMed]

24. Levett, P.N. Usefulness of serologic analysis as a predictor of the infecting serovar in patients with severe leptospirosis. Clin. Infect. Dis. 2003, 36, 447-452. [CrossRef] [PubMed]

25. Villumsen, S.; Pedersen, R.; Krogfelt, K.A.; Jensen, J.S. Expanding the Diagnostic Use of PCR in Leptospirosis: Improved Method for DNA Extraction from Blood Cultures. PLoS ONE 2010, 5, e12095. [CrossRef]

26. Gonçalves, A.T.; Paiva, C.; Melo-Mota, F.; Vieira, M.L.; Carreira, T.; Nunes, M.S.; Mota-Vieira, L.; Ahmed, A.; Harstkeerl, R.A.; Hyde, K.; et al. First isolation of human Leptospira strains, Azores, Portugal. Int. J. Infect. Dis. 2010, 14. [CrossRef]

27. Ellinghausen, H.C.; McCullough, W.G. Nutrition of Leptospira Pomona and growth of 13 other serotypes: A. Am. J. Vet. Res. 1965, 26, 39-44.

28. Adler, B.; de la Peña Moctezuma, A. Leptospira and Leptospirosis, 2nd ed.; MedSci: Armadale, Australia, 1999; p. 293.

29. Wuthiekanun, V.; Amornchai, P.; Paris, D.H.; Langla, S.; Thaipadunpanit, J.; Chierakul, W.; Smythe, L.D.; White, N.J.; Day, N.P.; Limmathurotsakul, D.; et al. Rapid isolation and susceptibility testing of Leptospira spp. using a new solid medium, LVW agar. Antimicrob. Agents Chemother. 2013, 57, 297-302. [CrossRef]

30. Clarridge, J.E.; Alerts, C. Impact of $16 \mathrm{~S}$ rRNA gene sequence analysis for identification of bacteria on clinical microbiology and infectious diseases. Clin. Microbiol. Rev. 2004, 17, 840-862. [CrossRef] [PubMed]

31. Pereira, M.M.; Matsuo, M.G.; Bauab, A.R.; Vasconcelos, S.A.; Moraes, Z.M.; Baranton, G.; Saint Girons, I. A clonal subpopulation of Leptospira interrogans sensu stricto is the major cause of leptospirosis outbreaks in Brazil. J. Clin. Microbiol. 2000, 38, 450-452. 
32. Thaipadungpanit, J.; Wuthiekanun, V.; Chierakul, W.; Smythe, L.D.; Petkanchanapong, W.; Limpaiboon, R.; Apiwatanaporn, A.; Slack, A.T.; Suputtamongkol, Y.; White, N.J.; et al. A Dominant Clone of Leptospira interrogans Associated with an Outbreak of Human Leptospirosis in Thailand. PLoS Negl. Trop. Dis. 2007, 1, e56. [CrossRef]

33. Cosate, M.R.; Sakamoto, T.; de Oliveira Mendes, T.A.; Moreira, É.C.; da Silva, C.G.; Brasil, B.S.; Oliveira, C.S.; de Azevedo, V.A.; Ortega, J.M.; Leite, R.C.; et al. Molecular typing of Leptospira interrogans serovar Hardjo isolates from leptospirosis outbreaks in Brazilian livestock. BMC Vet. Res. 2017, 13, 177. [CrossRef] [PubMed]

34. Brenner, D.J.; Kaufmann, A.F.; Sulzer, K.R.; Steigerwalt, A.G.; Rogers, F.C.; Weyant, R.S. Further determination of DNA relatedness between serogroups and serovars in the family Leptospiraceae with a proposal for Leptospira alexanderi sp. nov. and four new Leptospira genomospecies. Int. J. Syst. Bacteriol. 1999, 49, 839-858. [CrossRef] [PubMed]

35. Smith, D.J.; Brown, H.E.; Tonge, J.I.; Sinnamon, C.N.; MacDonald, V.M.; Ross, C.J.; Doherty, R.L. The serological classification of 89 strains of leptospirae from North Queensland. Aust. Ann. Med. 1954, 3, 98-105. [PubMed]

36. Slack, A.T.; Symonds, M.L.; Dohnt, M.F.; Corney, B.G.; Smythe, L.D. Epidemiology of Leptospira weilii serovar Topaz infections in Australia. Commun. Dis. Intell. 2007, 31, 216-222.

37. Johnson, R.C.; Rogers, P. 5'-fluorouracil as a selective agent for growth of leptospirae. J. Bacteriol. 1964, 87, 422-426. [CrossRef]

38. Turner, L.H. Leptospirosis III. Maintenance, isolation and demonstration of leptospires. Trans. R. Soc. Trop. Med. Hyg. 1970, 64, 623-646. [CrossRef]

39. WHO Expert Group on Leptospirosis. Current problems in leptospirosis research. WHO Tech. Rep. Ser. 1967, $380,1-32$.

(C) 2020 by the authors. Licensee MDPI, Basel, Switzerland. This article is an open access article distributed under the terms and conditions of the Creative Commons Attribution (CC BY) license (http://creativecommons.org/licenses/by/4.0/). 